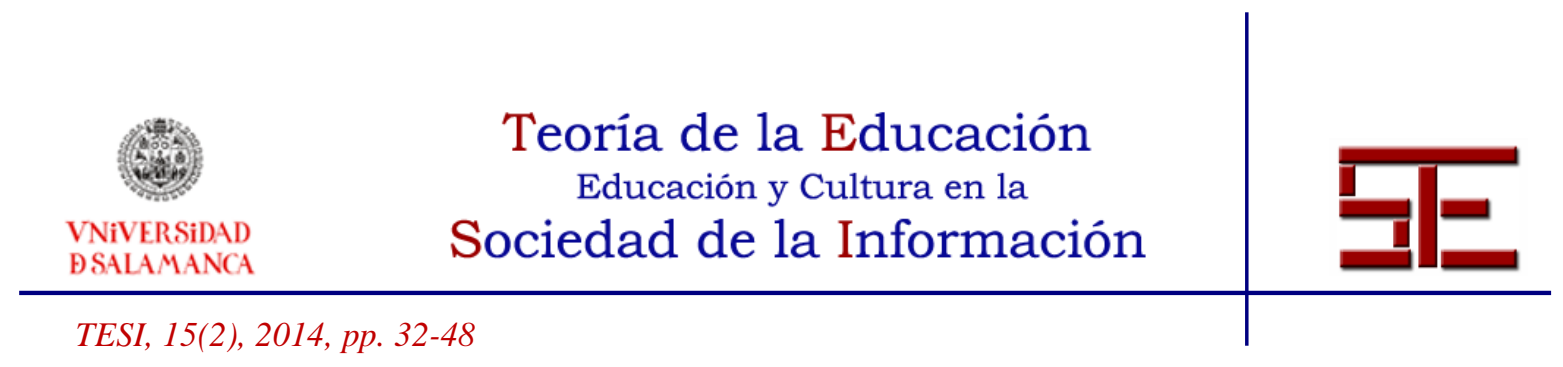

\title{
OBJETO DE APRENDIZAJE PARA LA FORMACIÓN DOCENTE ORIENTADO A DESARROLLAR COMPETENCIAS PARA USAR REA ${ }^{1}$
}

Resumen: El presente artículo tiene como objetivo presentar los resultados de una investigación relacionada con el diseño y uso de un Objeto de Aprendizaje Abierto (en adelante OA). Se usó una metodología de enfoque cualitativo y la entrevista electrónica aplicada a docentes y a expertos que tuvieron a cargo la validación objetiva del OA, se respondió la siguiente pregunta de investigación: ¿En qué medida un recurso orientado a desarrollar competencias para usar Recursos Educativos Abiertos para la práctica educativa cumple con un conjunto de criterios de calidad preestablecidos de acuerdo con aquello que caracteriza a los objetos de aprendizaje abiertos? Los resultados indican que el objeto de aprendizaje cumplió de forma efectiva con los estándares y especificaciones en cuanto al aspecto pedagógico y tecnológico sin embargo, existieron aspectos tales como: errores conceptuales, actividades, evaluación, entre otros, que fueron considerados para revisarse e inclusive modificarse para que el OA en cuestión se considere un objeto de aprendizaje de calidad. Se destaca el hecho de que el tema de la presente investigación constituye una innovación y una herramienta útil y necesaria para las actuales demandas del quehacer docente.

Palabras clave: Objeto de aprendizaje; Recursos Educativos Abiertos; competencias docentes; REA en la práctica educativa.

\footnotetext{
${ }^{1}$ Esta investigación se desarrolló en el marco del Proyecto "Evaluar para mejorar: Sistema de evaluación educativa para escuelas de bajo logro académico" (http://tecvirtual.itesm.mx/convenio/tabasco/homedoc.htm) del Fondo Mixto de Fomento a la Investigación Científica y Tecnológica CONACYT - Gobierno del Estado de Tabasco (TAB - 2008 - C13 - 94053), con el apoyo de la Cátedra de Investigación de Innovación en Tecnología y Educación del Tecnológico de Monterrey (http://www.ruv.itesm.mx/convenio/catedra/homedoc.htm). Se otorga un reconocimiento especial a ambas instancias por el apoyo recibido para realizar este estudio.
}

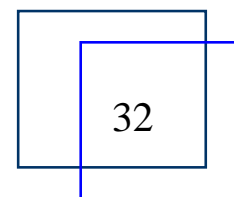




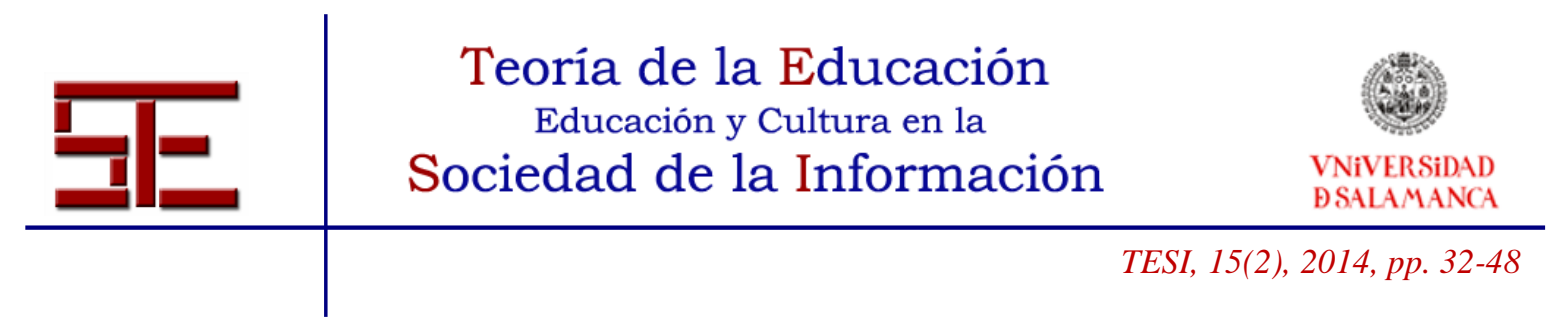

\title{
LEARNING OBJECT FOR TEACHER TRAINING ORIENTED TO DEVELOP SKILLS TO USE OER
}

\begin{abstract}
This article aims to present the results of an investigation related to the design and use of an Open Learning Object.

Using a qualitative methodology approach and electronic applied interviews to some of the experts who were in charge of evaluate the Learning Object, the following research question was answered: How much does the Open Educational Resource designed to enhance educational practice, meets a set of established quality criteria that characterizes the Open Learning Objects? The obtained results indicate that the learning object fulfilled effectively with the standards and specifications concerning the pedagogical and technological aspects, however there were some other aspects such as misconceptions, activities and evaluation that were considered to be reviewed and even changed in order to considered the Open Learning Object as a high quality one. It is worthy of note the fact that the subject of the present investigation is considered an innovation and also a necessary and useful tool for the current demands of teaching work.
\end{abstract}

Key words: learning object; open educational resources; teaching skills; OER in educational practice. 


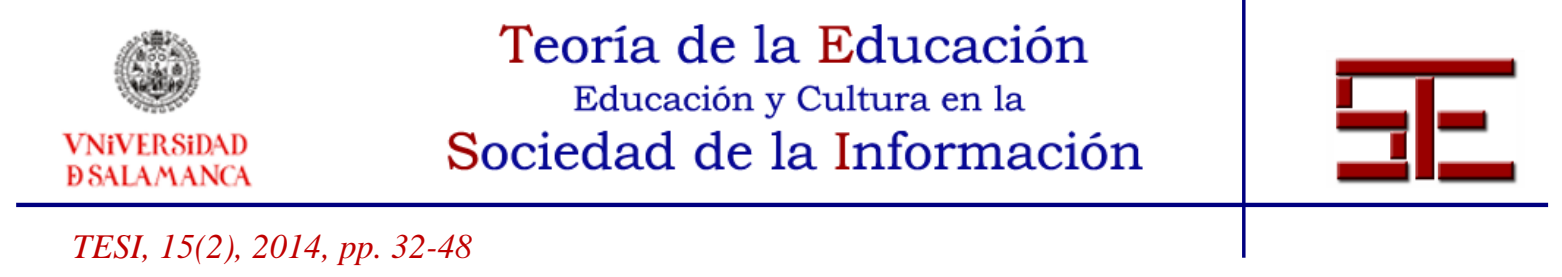

\title{
OBJETO DE APRENDIZAJE PARA LA FORMACIÓN DOCENTE ORIENTADO A DESARROLLAR COMPETENCIAS PARA USAR REA
}

Fecha de recepción: 27/01/2014; fecha de aceptación: 11/03/2014; fecha de publicación: 30/06/2014

\begin{abstract}
Ahabael Lugo López
ahabael_lugo@hotmail.com
\end{abstract}

Tecnológico de Monterrey

Fernando Gustavo Lozano Martínez

fernando.lozano@itesm.mx

Tecnológico de Monterrey

María Soledad Ramírez Montoya

solramirez@itesm.mx

Tecnológico de Monterrey

\section{1.- INTRODUCCIÓN}

En virtud de que el desarrollo de las competencias en la práctica educativa es un tema de actualidad y, por otro lado, la utilidad que presentan los objetos de aprendizaje como una herramienta innovadora para generar conocimiento, se presenta el siguiente estudio. La sociedad basada en el conocimiento precisa de herramientas y conceptos globales, que se puedan interpretar y aplicar en diferentes contextos, como lo menciona Valenzuela (2009). Se requiere también que la formación docente incluya el desarrollo y uso de competencias. Aunado a lo anterior, la formación docente demanda la búsqueda de recursos, estrategias y alternativas como un factor clave en una sociedad basada en el conocimiento (Ramírez y Valenzuela, 2010).

Es precisamente en este marco que se presenta el siguiente estudio, considerado como una experiencia en el desarrollo, implementación y evaluación de un objeto de aprendizaje, el cual se basó en un estudio llamado "Evaluar para mejorar: Sistema de evaluación educativa para escuelas de bajo logro académico" apoyado por el Fondo Mixto CONACYT - Tabasco (2009-2011).

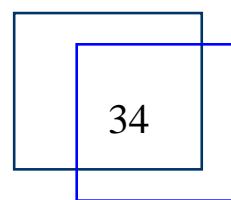




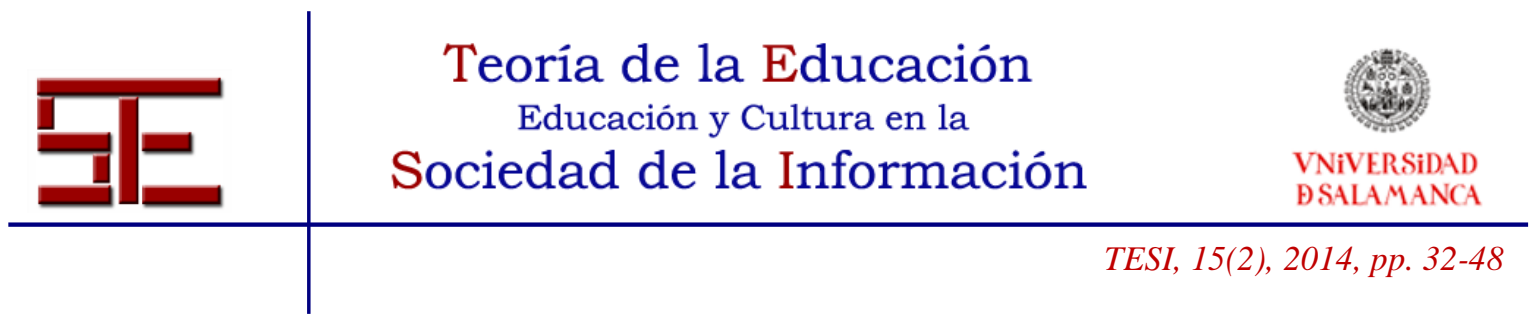

Cabe mencionar que este estudio se desarrolló en varias etapas: diseño del sistema de evaluación, aplicación de instrumentos de medición y análisis de resultados, elaboración de objetos de aprendizaje y capacitación de profesores. La investigación que se presenta en este artículo se ubica en la tercera etapa correspondiente a la capacitación de profesores. Se trabajó en conjunto con dos instituciones, por un lado, un Instituto de Estudios Superiores donde se aplicó el OA a los docentes, quienes evaluaron su calidad y, por otro lado, con el grupo de la Cátedra de Investigación de Innovación en Tecnología y educación del Instituto Tecnológico y de Estudios Superiores de Monterrey, que están encaminados a desarrollar estudios basados en tecnología. Los resultados pretenden aportar información que incidirá en la formación y práctica educativa.

\section{2.- REFERENTE TEÓRICO}

La formación docente es un tema que involucra y beneficia a todos los agentes educativos, organizaciones a nivel mundial tienen muy claro que es necesario realizar acciones en este sentido. La UNESCO (2004) aspira a desempeñar una función de primer orden a nivel mundial en el ámbito de la formación de docentes, apoyando así mismo, la revisión y elaboración de materiales de capacitación y la administración de dicho sector.

\subsection{Competencias docentes}

En México, una de las temáticas en la educación que están generando más atención son las competencias, ya que dicho concepto está incluido en la reciente Reforma Educativa; por lo tanto, se están haciendo aproximaciones en las distintas Instituciones para capacitar a los docentes y generar estrategias que permitan el desarrollo de estas habilidades.

La Secretaria de Educación Pública ha venido realizando algunas actividades para formar a los docentes en competencias, un apartado de la Reforma Educativa lo constituye la reforma de los contenidos, esto necesariamente abarca actividades como idear nuevos modelos académicos y estrategias pedagógicas, entre otros asuntos que requiere reformas en el plano de la gestión universitaria (Luengo, 2003).

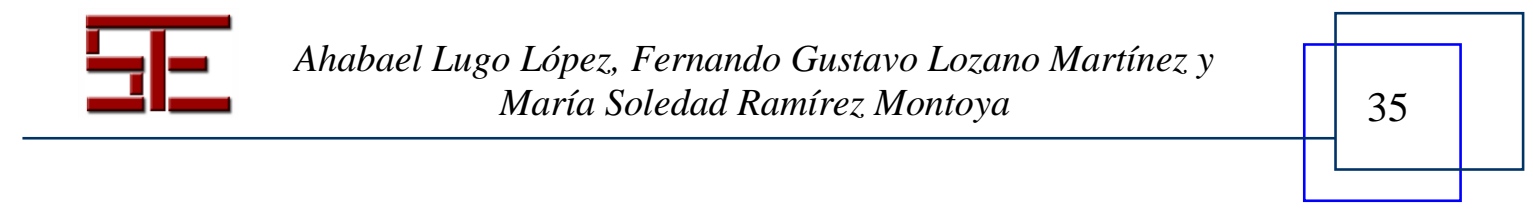




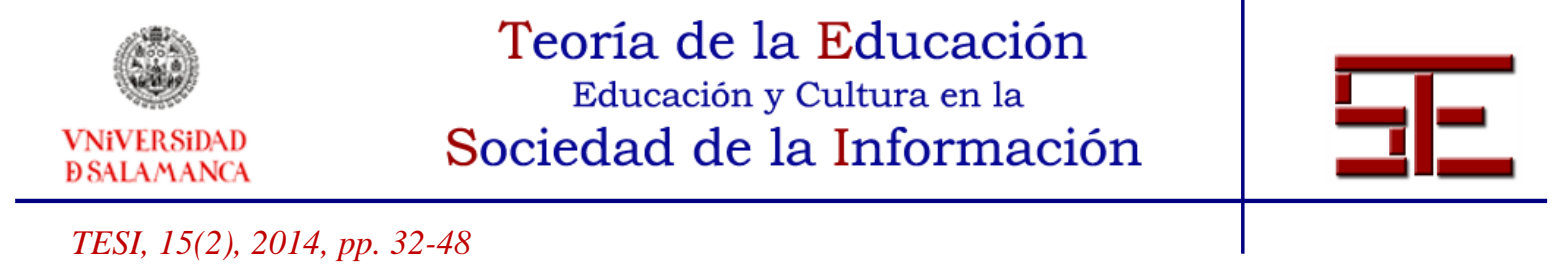

\subsection{Definición y características de los Recursos Educativos Abiertos}

La idea de Recursos Educativos Abiertos, REA, abarca contenidos educativos como texto, sonido, video, que tienen licencia libre, que facilitan la producción, la distribución y el uso de dichos contenidos. Pero también existen diferentes posturas en la definición de los REA, Atkins, Brown \& Hammond (2007), D’Antoni (2008), Geser (2007), Salinas (1999), Schettler (2002), Schmidt (2007), Sicilia (2007) y Vercelli (2004). Una de las características de estos recursos son las licencias suplementarias abiertas como las de Creative Commons. Esto genera que con mayor frecuencia se publiquen contenidos abiertos y también se adopten a las prácticas educativas. Schmidt (2007) menciona otra ventaja, ya que cada vez más profesores crean versiones digitales de sus materiales y las comparten con sus alumnos, supone un pequeño paso publicarlos también en un sitio web para que otros puedan descargarlos. Para Gil, Candelas y García (2012), los REA son considerados una herramienta eficaz para motivar el aprendizaje.

\subsection{Competencias para usar recursos educativos abiertos para la práctica educativa}

El concepto de competencia implica en sí mismo varias acepciones, Zabalza (2003) lo define "como un conjunto molar que nos sirve para referirnos al conjunto de conocimientos y habilidades que los sujetos necesitamos para desarrollar algún tipo de actividad" (p. 70). Dicho concepto no es nuevo, y existen diferentes posturas al respecto que clasifican a las competencias en distintas áreas: Arteaga y García (2007), Ballesteros y otros (2002), Bolívar (2007), Carton (1985), Evers, Rush \& Berdrow (1998), García y otros (2008), Hougton (2007), Oliveros (2006), Phillips (2009), Sullivan \& Higgins (1983) y Zabalza (2003) hablan de competencias del perfil docente, del trabajo, de la persona, habilidades clave, de competencia laboral, científicas, de docente virtual, etc.

En específico, las competencias que se desarrollan al utilizar los Recursos Educativos Abiertos (REA) se pueden enumerar de la siguiente manera: tener una actitud crítica y constructiva; conocer las posibilidades de las nuevas tecnologías; seleccionar, utilizar, diseñar y producir materiales didácticos utilizando las nuevas tecnologías que promuevan la adquisición de aprendizaje significativo, y que convierta el aula en un laboratorio desde el cual se promueve el protagonismo y la responsabilidad de los alumnos (Fernández, 2004). Valenzuela (2009) menciona que la competencia del uso de REA se desarrolla con base en la siguiente secuencia:

1)Darse cuenta de que existen

2)Conocer que hay catálogos completos

3)Explorar los REA

4)Entender en qué consisten

5)Distinguir las ventajas y desventajas

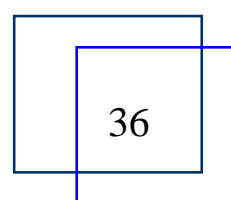

Ahabael Lugo López, Fernando Gustavo Lozano Martínez y María Soledad Ramírez Montoya

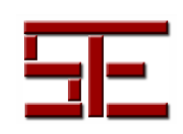




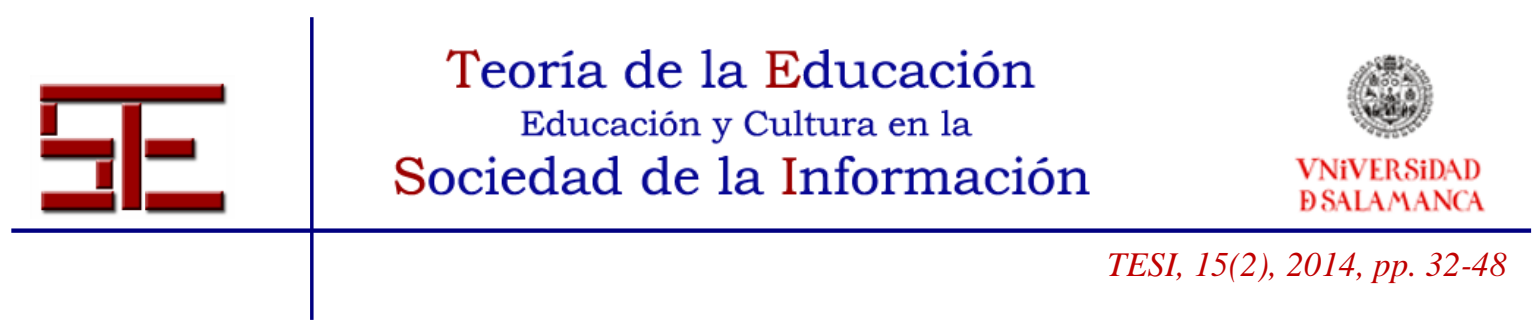

6)Discriminar cuáles recursos se pueden adoptar

\subsection{Objetos de aprendizaje abiertos}

En el caso del contexto educativo, y específicamente tratándose de un curso en línea, un objeto de aprendizaje es definido como un objeto digital utilizado con el fin de alcanzar resultados de aprendizaje deseados (Smith, 2005). Para Murphrey, Sandlin y Dooley (2013), los objetos de aprendizaje abiertos y reutilizables tienen un gran potencial en el alcance que pueden lograr con ellos los educadores, pero para ello deben ser desarrollados de tal manera que brinden un valor agregado tanto a instructores como a los estudiantes que harán uso de ellos.

\section{3.- MARCO METODOLÓGICO}

Esta investigación se basó en el estudio "Evaluar para mejorar: Sistema de evaluación educativa para escuelas de bajo logro académico" (apoyado por el Fondo Mixto CONACYT-Tabasco, 2009-2011). El objetivo consistía en analizar los componentes pedagógicos y tecnológicos de un OA, a partir de la producción de un OA que fue sometido al análisis de docentes y expertos. En este estudio se contó con el apoyo de expertos de tecnología, producción y diseño gráfico, quienes elaboraron el diseño instruccional, pedagógico y tecnológico del objeto de aprendizaje. La investigación se desarrolló en función de la siguiente pregunta de investigación: ¿En qué medida un recurso orientado a desarrollar competencias para usar Recursos Educativos Abiertos para la práctica educativa, diseñado para la formación de profesores, sobre competencias genéricas para una sociedad basada en conocimiento, cumple con un conjunto de criterios de calidad preestablecidos de acuerdo con aquello que caracteriza a los objetos de aprendizaje abiertos?

El método utilizado fue cualitativo de tipo exploratorio y con validación de expertos, cada uno de ellos proporcionó distintos datos, los cuales fueron codificados para dar respuesta a la pregunta de investigación. Schwandt (citado por Carter \& Little en 2007) define como investigación social al investigador que se basa en datos de texto, y posteriormente analiza esos datos en su forma textual, en realidad, busca entender la acción humana. Esta investigación se basó en una crítica realista; una modificación subjetiva; y que se aterriza en una triangulación, esto es, que el investigador encuentra información en distintas fuentes de datos, de investigadores, teorías y métodos (Guba, 1990). La muestra elegida para este estudio fueron 40 docentes, a partir de una selección aleatoria y funcional. Aunado a lo anterior, se incluyeron participantes de distintas especialidades profesionales, dos expertos en cada una de las siguientes áreas: contenido, pedagogía, diseño gráfico y en tecnología.

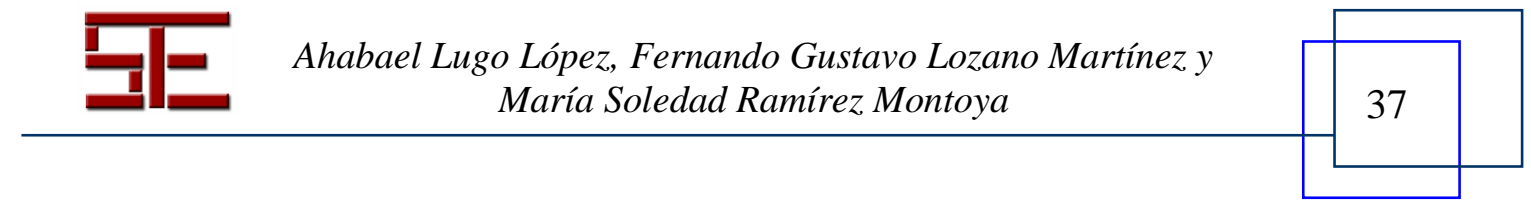




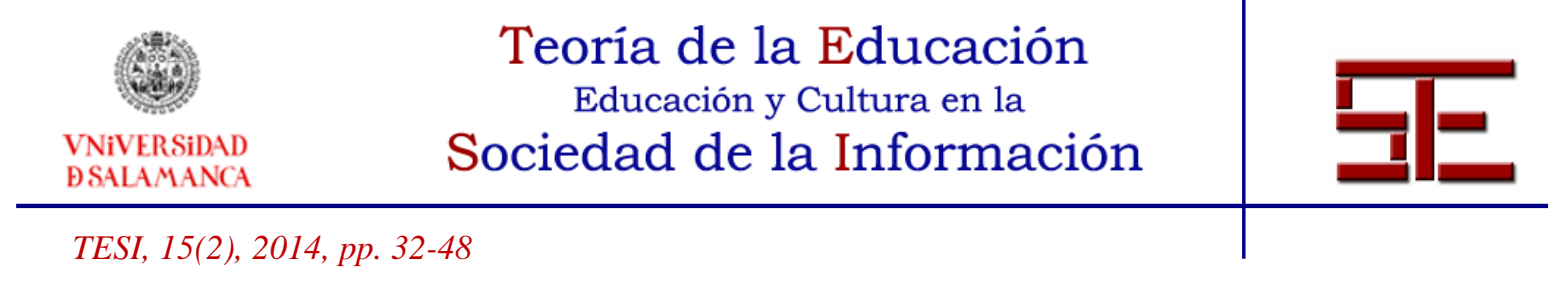

La investigación tuvo una validación de expertos en cinco áreas: contenido, pedagogía, tecnología, diseño gráfico y los usuarios del objeto de aprendizaje. En el área de contenido fue el experto en la competencia del OA. En el de pedagogía fue el experto en diseño instruccional en educación y que proporcionó información sobre el aspecto didáctico para que se lograra el aprendizaje. El de tecnología fue el experto en informática y tecnología que proporcionó información en relación a los aspectos tecnológicos de reusabilidad, peso, estructura tecnológica y otros. El de diseño gráfico fue el experto en diseño gráfico y comunicación que apoyó en la revisión del lenguaje gráfico y textual. Los usuarios fueron los profesores que utilizaron el objeto de aprendizaje y que proporcionaron información al detectar las potencialidades y debilidades del recurso.

\subsection{Descripción del objeto de aprendizaje para desarrollar competencias para usar recursos educativos abiertos para la práctica educativa}

Desarrollo del objeto de aprendizaje abierto. El objeto de aprendizaje se diseñó primero a partir del siguiente esquema: a) elaboración del contenido del objeto a través del desglose de seis temáticas, b) ajuste del contenido a plantillas establecidas de trabajo, c) revisión por un experto en contenido y pedagogía, d) elaboración del objeto en el aspecto tecnológico y con apoyo de diseño gráfico. El objeto de aprendizaje se encuentra disponible en los espacios siguientes:

-Lugo, A. (2010). Competencia para usar recursos educativos abiertos para la práctica educativa [objeto de aprendizaje]. Disponible en el sitio Web:http://www.ruv.itesm.mx/convenio/tabasco/oas/ureape/homedoc.ht $\mathrm{m}$ y en el Repositorio abierto de la cátedra de investigación de innovación en tecnología y educación del Tecnológico de Monterrey en: http://catedra.ruv.itesm.mx//handle/987654321/250

La estructura del objeto tenía los siguientes elementos: resumen, información general (introducción, objetivo, temario), evaluación diagnóstica y final, temas (actividad inicial, contenido, actividad final, recursos), referencias y créditos. Cada uno de estos elementos se desglosó primero en tres distintas plantillas, y posteriormente se trabajó la parte tecnológica con un equipo multidisciplinario que a partir de ellas construyó el objeto. La competencia a desarrollar fue el uso de los recursos educativos abiertos (ver Figura 1).

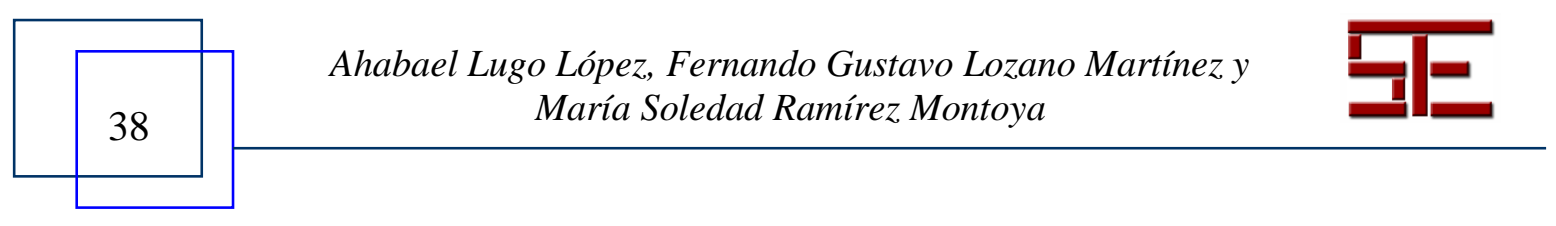



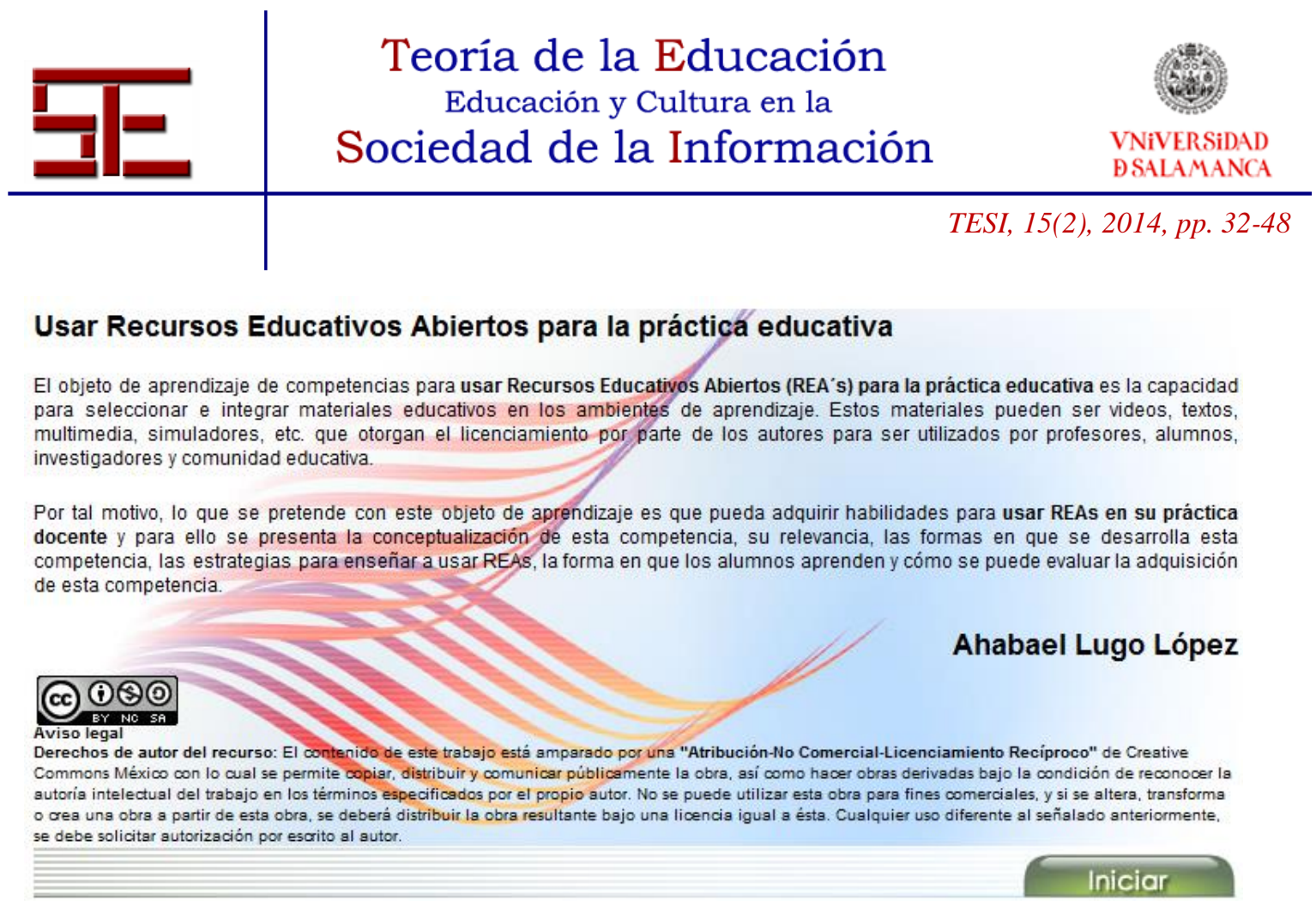

Figura 1. Página inicial del objeto de aprendizaje

\subsection{Componentes didácticos del objeto}

Se presentó primero una evaluación diagnóstica y después seis temas que se fueron desarrollando, para posteriormente realizar una evaluación. El contenido se presentó en seis temas a modo de pregunta, el desarrollo del contenido de cada uno fue redactado de forma independiente: ¿Cómo se conceptualiza la competencia para usar recursos educativos para la práctica educativa? ¿Por qué es relevante esta competencia para una sociedad basada en conocimiento? ¿Cómo las personas desarrollan una competencia? ¿Cómo es posible enseñar esta competencia a los alumnos? ¿Cómo los alumnos aprenden una competencia? ¿Cómo el profesor puede evaluar si sus alumnos han desarrollado una competencia?.

Al finalizar cada tema, el usuario contestó un ejercicio que permitió validar el aprendizaje obtenido, a esto se le denominó actividad final, y que también era un ejercicio breve y sencillo con retroalimentación específica. La evaluación consistió en un ejercicio que permitiera reconocer el aprendizaje obtenido a lo largo del objeto con reactivos bien estructurados y con retroalimentación inmediata (ver Figura 2).

Ahabael Lugo López, Fernando Gustavo Lozano Martínez y María Soledad Ramírez Montoya 

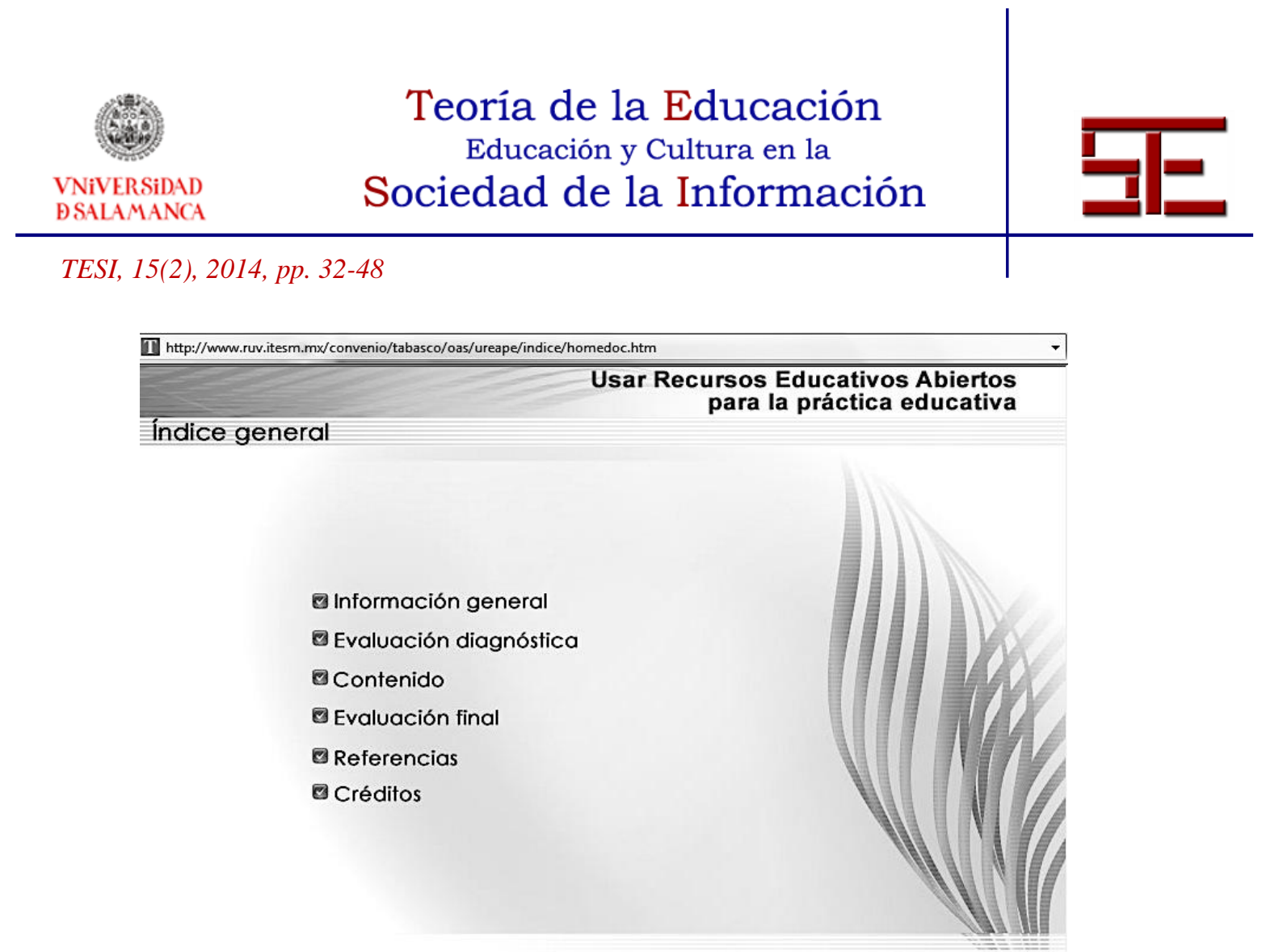

Figura 2. Índice general del objeto de aprendizaje

\subsection{Componentes tecnológicos del objeto}

En esta sección se trabajó con dos especialistas en programación, quienes aterrizaron los contenidos de las plantillas e incorporaron recursos y materiales en su elaboración. Ellos fueron quienes en forma de asesoría estuvieron indicando y trabajando en conjunto con el armado tecnológico del objeto. Se incluyeron imágenes que facilitaron el aprendizaje de los usuarios.

\subsection{Componentes gráficos y textuales del objeto}

La presentación del objeto de aprendizaje tuvo los siguientes elementos: imágenes, gráficos y colores. Sobre las imágenes utilizadas, se buscaron aquellas que permitieran el reforzamiento de algún concepto. Gráficos: en la parte superior se encontraba el resumen, la información general, evaluación diagnóstica, tema 1 , tema 2 , tema 3 , tema 4 , tema 5, tema 6 , evaluación final, referencias y créditos. Colores: se requirieron colores neutros, en la parte superior se utilizó un color azul de fondo y letras en color blanco. En el centro de la página el fondo era blanco para que se facilitara la lectura. En relación al manejo de la información textual, en cada descripción del tema, se presentó poca información, únicamente la esencial, con colores básicos, como el negro, para que fuera de fácil lectura para el usuario (ver Figura 3).

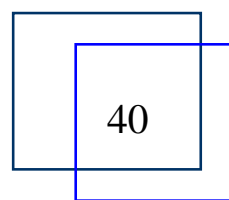

Ahabael Lugo López, Fernando Gustavo Lozano Martínez y María Soledad Ramírez Montoya 

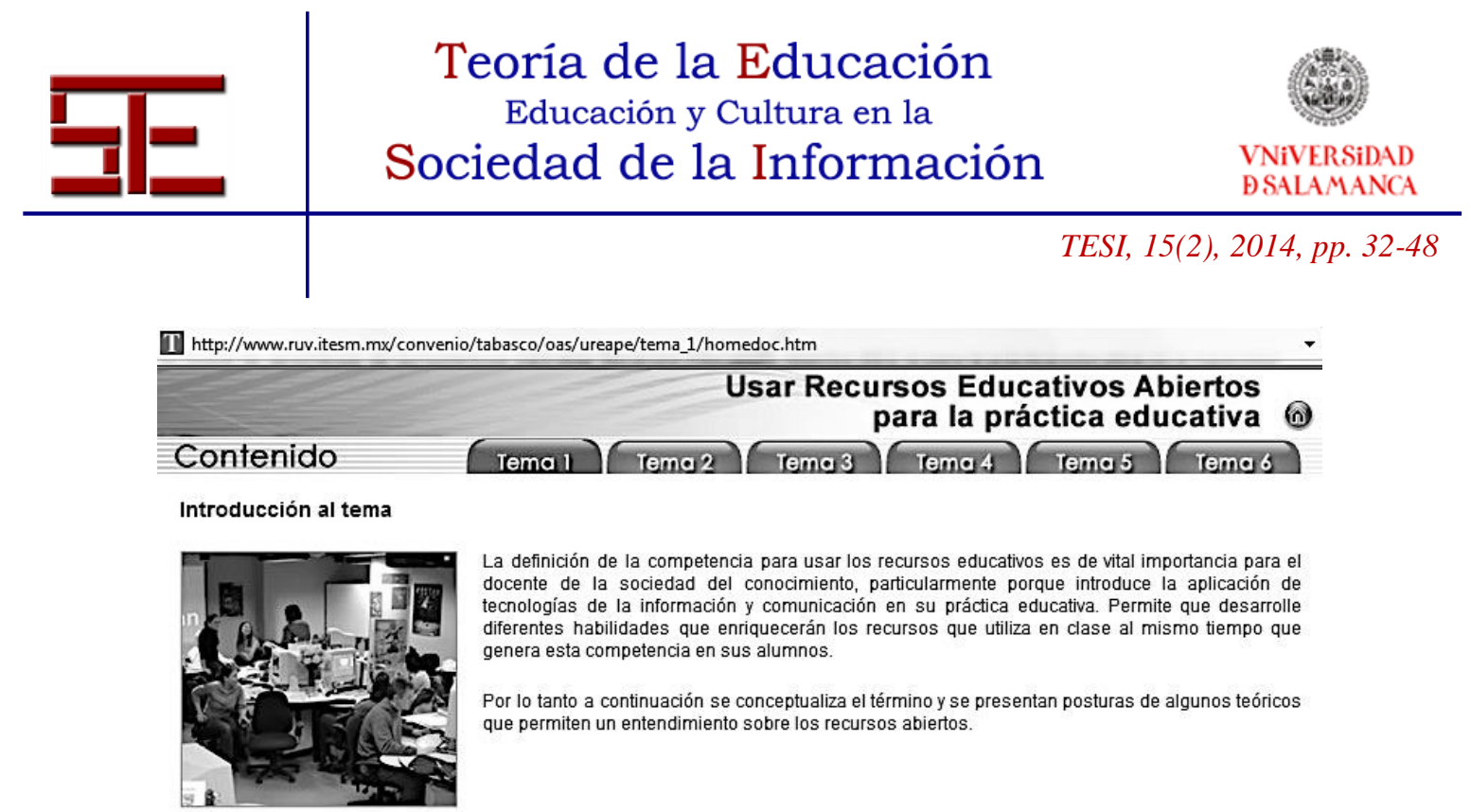

Tema 1 - Páginas: Al| I|1| $2|3| 4|C|$ AF $\mid R$

Figura 3. Contenido del Objeto de Aprendizaje

Posteriormente se aplicaron cuestionarios electrónicos a los expertos participantes en esta investigación. Se contó con la participación de dos expertos por cada área a evaluar, y con el apoyo de 40 usuarios/profesores que contestaron las preguntas. Los resultados indican el número de frecuencias registradas en cada pregunta de cada indicador. Cada indicador tuvo un rango de entre dos a seis preguntas. Las opciones de respuesta fueron: completamente de acuerdo, de acuerdo, en desacuerdo y totalmente en desacuerdo.

El cuestionario para docentes exploró la relevancia, alcance, objetivos de aprendizaje, motivación, evaluación, usabilidad, accesibilidad, reusabilidad, sintaxis gráfica, semántica del OA. Los cuestionarios electrónicos para el experto en contenido y de pedagogía estaban basados en todos los indicadores. Los cuestionarios para el experto en tecnología y diseño gráfico evaluaron únicamente la usabilidad, accesibilidad, reusabilidad y sintaxis gráfica. El manejo de datos se realizó a través de la transcripción de los resultados obtenidos y se utilizó un cuadro de triple entrada para la triangulación de datos. El objetivo de estos últimos era obtener información sobre las fortalezas que identificaron en el objeto y qué elementos sugerían para mejorarlo. Finalmente los resultados encontrados en todas las fuentes se triangularon para interpretar los resultados y tener una validación de expertos.

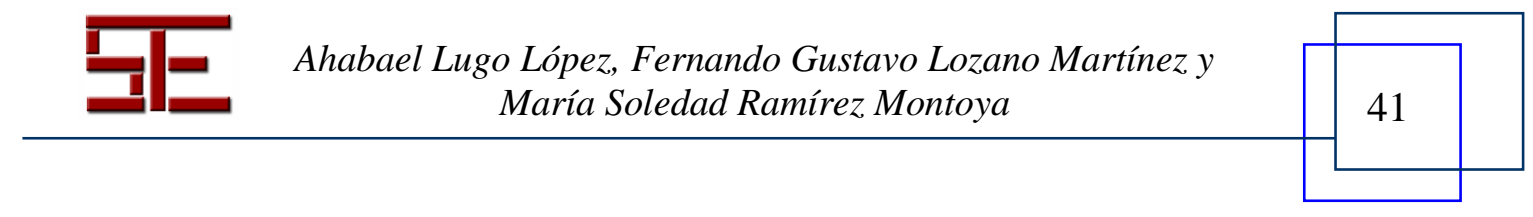




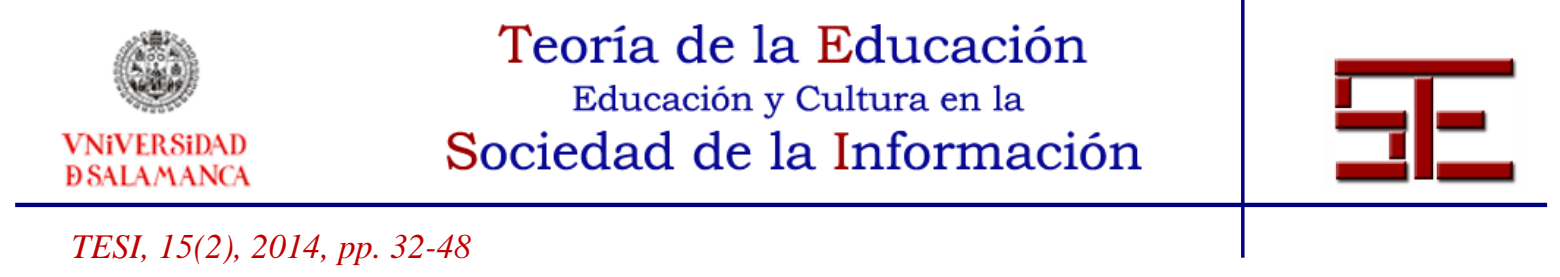

\section{4.- RESULTADOS}

Se encontraron distintos resultados en cada categoría. En el contenido del OA se presenta que hay relevancia en las competencias de los Objetos de Aprendizaje y alcance en el desarrollo de la competencia. En la categoría de pedagogía del objeto se presenta que hay objetivos de aprendizaje, motivación y evaluación. En tecnología de objeto existe usabilidad, accesibilidad y reusabilidad. En diseño gráfico se presenta la sintaxis gráfica y semántica del OA.

Los expertos mencionan que en el área de contenido debe efectuarse una revisión de las actividades, temas y del menú para elevar la navegación. En pedagogía sugieren la modificación de la evaluación, tamaño de letra, incorporación de recursos y situaciones problemáticas que relacionen los recursos educativos abiertos a escenarios que enfrentan los docentes en su práctica educativa, incorporar elementos multimedia, examinar proceso de enseñanza - aprendizaje, agregar más recursos adicionales. En tecnología proponen hacer más visible el botón home y añadir imágenes de personas. En relación al diseño gráfico sería pertinente incorporar más fotografías y evitar errores de dedo.

Las fortalezas que se encontraron se describen a continuación en la Figura 4.

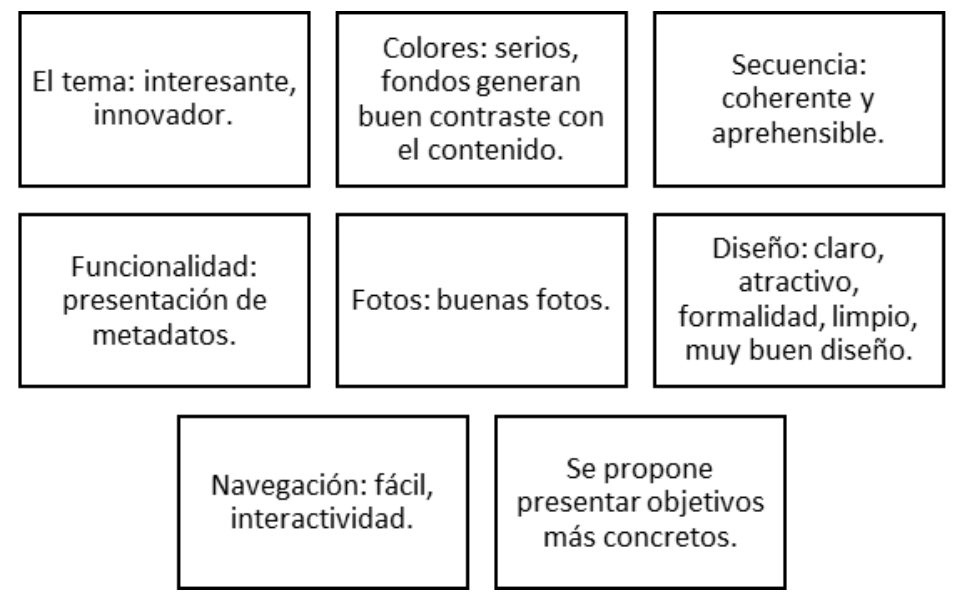

Figura 4. Fortalezas del OA

Fuente: Elaboración propia.

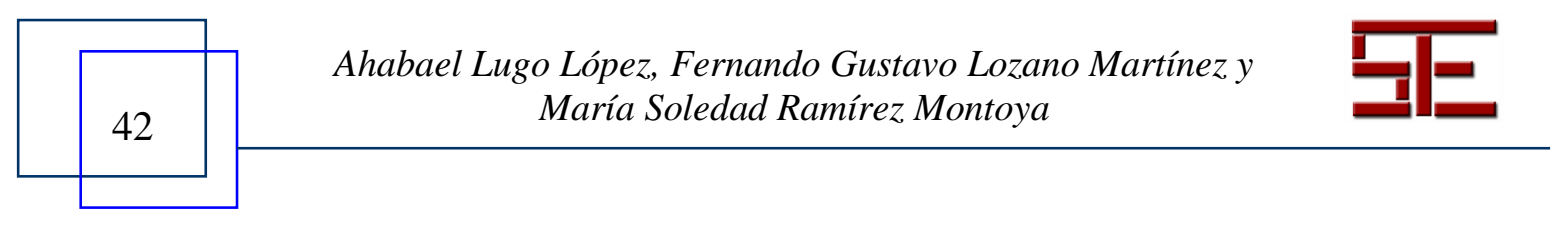




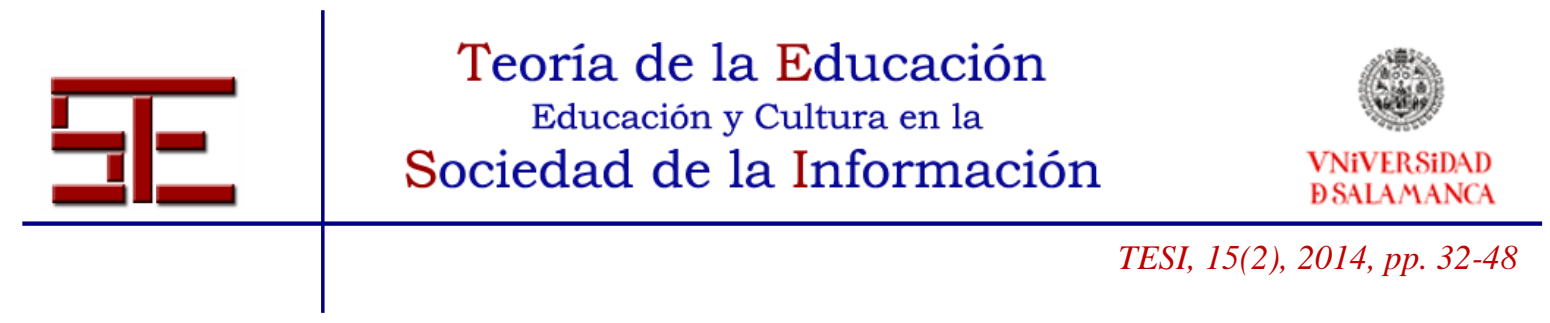

En cuanto a la categoría de Estructura pedagógica del objeto se encontró el siguiente resultado:

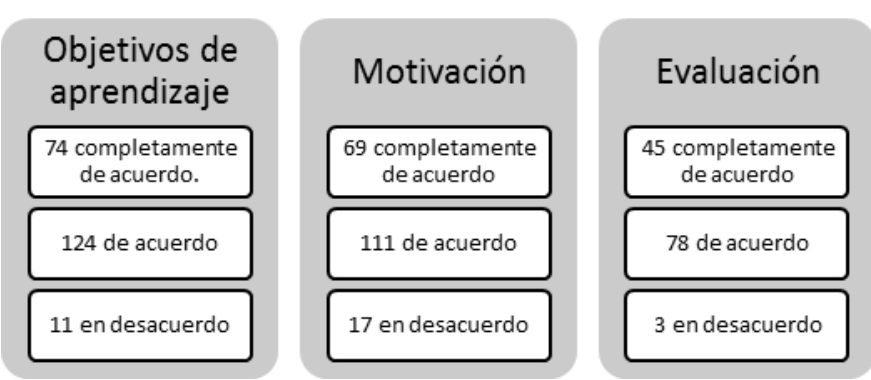

Figura 5. Resultados de contenidos de la competencia a aprender

Fuente: Elaboración propia.

En cuanto a la categoría de estructura tecnológica del objeto se encontró:

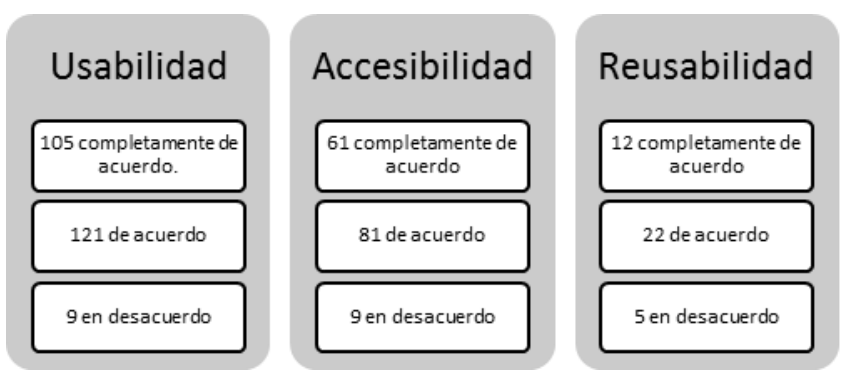

Figura 6. Resultados de la categoría de estructura tecnológica

Fuente: Elaboración propia.

En cuanto a la categoría de lenguaje gráfico y textual del objeto los resultados fueron:

Ahabael Lugo López, Fernando Gustavo Lozano Martínez y María Soledad Ramírez Montoya 

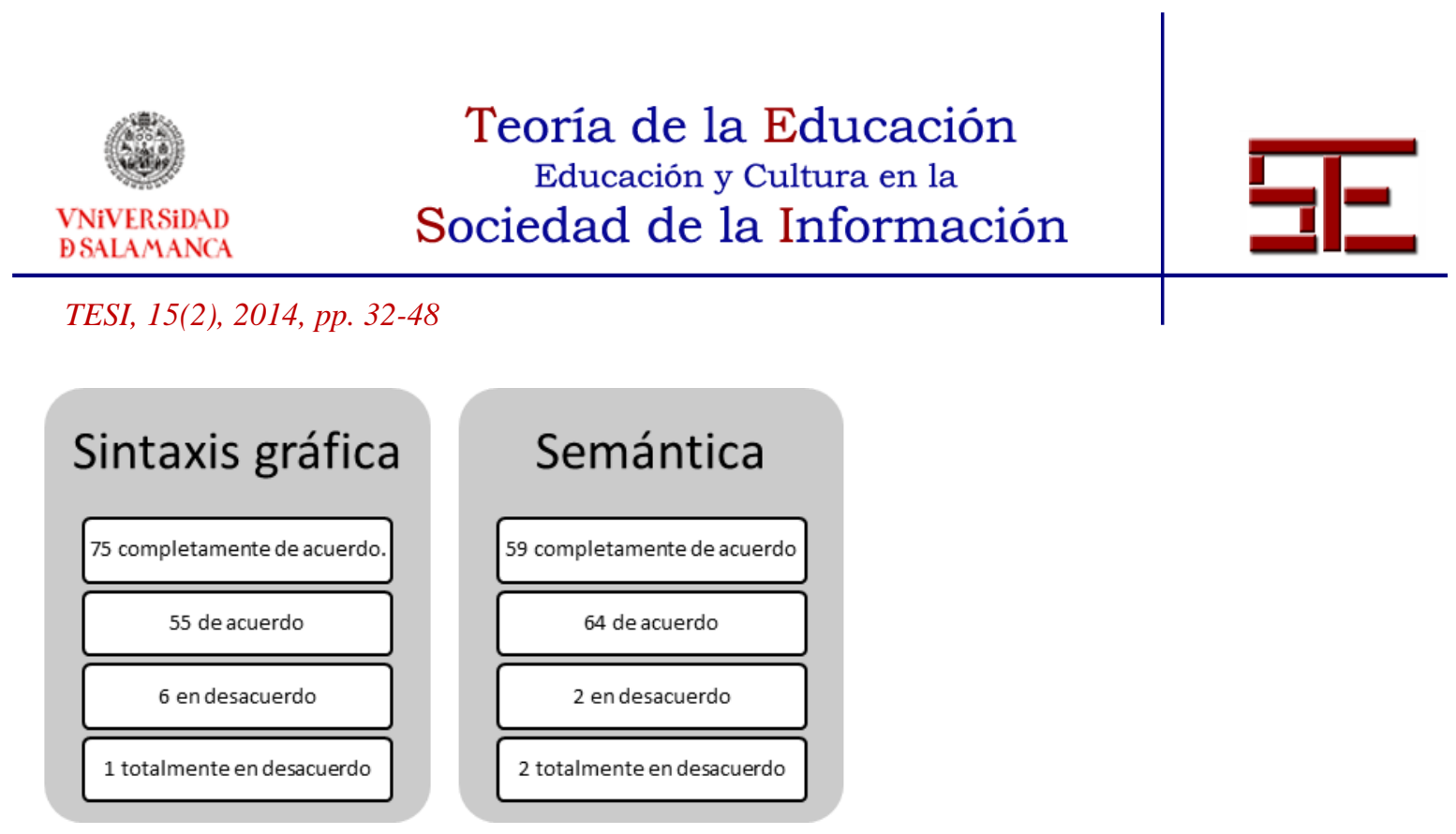

Figura 7. Resultados de la categoría de lenguaje gráfico y textual

Fuente: Elaboración propia

\section{5.- DISCUSIÓN Y CONCLUSIONES}

El objeto de aprendizaje diseñado para desarrollar la competencia de Recursos Educativos Abiertos pasó por un proceso de construcción, revisión, producción y evaluación. Todo ello con el fin de validarlo de acuerdo con los criterios establecidos de calidad en cuanto al contenido, estructura pedagógica, estructura tecnológica, lenguaje gráfico y textual y usabilidad del objeto de aprendizaje abierto. Esta validación permitió responder a la pregunta de investigación que se planteó al inicio: ¿Qué tanto un recurso orientado a desarrollar competencias para usar Recursos Educativos Abiertos para la práctica educativa, diseñado para la formación de profesores, sobre competencias genéricas para una sociedad basada en conocimiento, cumple con un conjunto de criterios de calidad preestablecidos de acuerdo con aquello caracteriza a los objetos de aprendizaje abiertos?

Los criterios a cubrir en el objeto de aprendizaje se refieren a dos grandes aspectos, el pedagógico y el tecnológico. En el primer caso se incluye el contenido y en el segundo hay una implicación del diseño gráfico. El primer criterio a considerar tiene que ver con el desarrollo del contenido pedagógico del objeto. Es sumamente necesario el trabajo exhaustivo en esta área. En el momento en que se redactó el contenido del objeto no se tenían las bases conceptuales necesarias y existía confusión en ciertos conceptos, por lo que se requiere un asesor temático, experto en el desarrollo de esta competencia, para detectar estos errores antes de la producción del OA.

Los expertos encontraron que es preciso revisar puntualmente los conceptos a manejar, en este caso dichos conceptos son: práctica educativa, aprendizaje significativo, capacidad para aprender, procesos de aprendizaje y enseñanza. Otros aspectos que

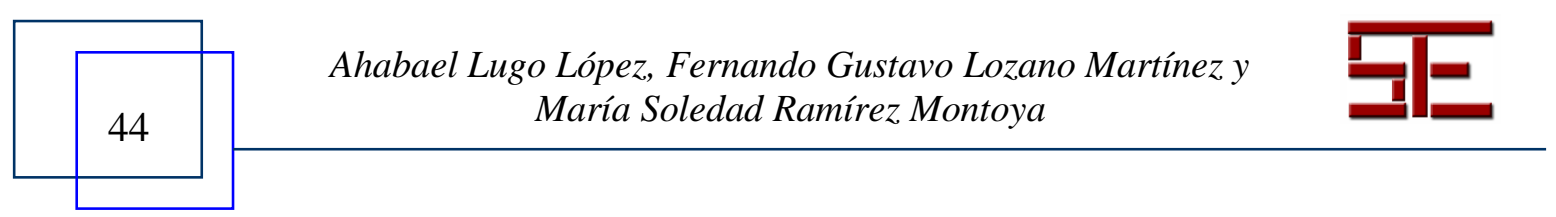




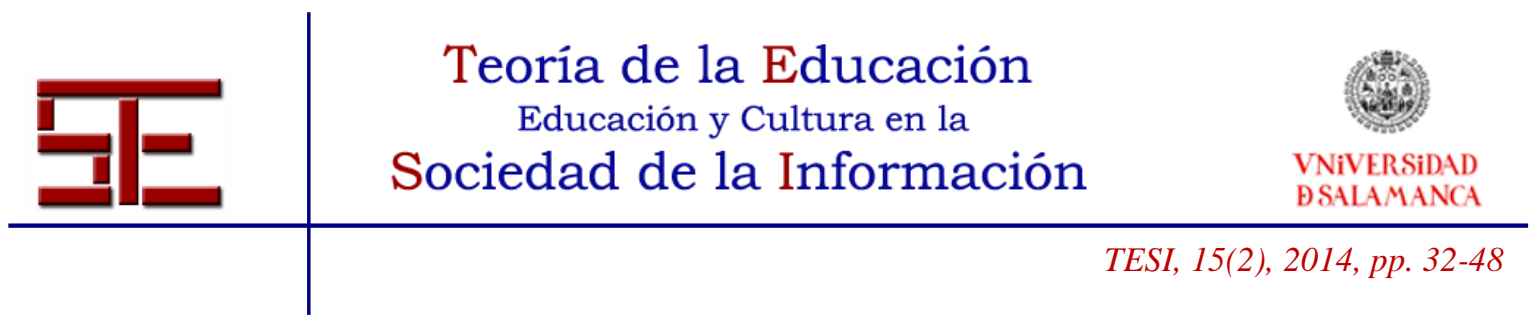

disminuyeron la calidad del recurso tienen que ver con objetivos que no se plantearon adecuadamente, errores ortográficos y estrategias de evaluación. Por tanto se requiere mucha labor en cuanto al contenido, el diseño instruccional y antes de pasar a la producción se acordó que estos aspectos deben ser revisados en varias ocasiones.

El segundo criterio de calidad es el de la estructura tecnológica que incluye la usabilidad, accesibilidad y reusabilidad. La usabilidad se manifestó en una fácil navegación derivada de texto concreto y elementos que hacían amigable la interacción con el recurso, así lo manifestaron los usuarios y expertos, concretando este aspecto como clave para el buen funcionamiento del OA.

Para estudios posteriores se sugiere lo siguiente: en relación con los temas, realizar una revisión más exhaustiva de la literatura disponible acerca de cómo es que tiene lugar el desarrollo de la competencia en el docente y en el alumno. En cuanto a la elaboración del objeto de aprendizaje, se sugiere revisar a profundidad los aspectos pedagógicos que involucran estrategias de aprendizaje y enseñanza, diseño instruccional y evaluación; así mismo es pertinente trabajar en el proceso de elaboración del objeto contando con el apoyo de asesores experimentados en cuanto a pedagogía y diseño gráfico.

Finalmente, no podemos soslayar el hecho de que los avances tecnológicos van a un ritmo acelerado y si pretendemos como educadores incidir en esa realidad cambiante se hace imperativo el desarrollo de las competencias, vencer las resistencias y construir OA pertinentes y de carácter abierto para toda la comunidad académica.

\section{6.- BIBLIOGRAFÍA}

Arteaga, M. \& García, M. (2007). La formación de competencias docentes para incorporar estrategias adaptativas en el aula. Revista Complutense de Educación, 19 (2), 253-274. Recuperado del Proquest Educational Journal ID 1938520571.

Atkins, D., Brown, J. \& Hammond, A. (2007). A review of the Open Educational Resources (OER) Movement: Achievements, Challenges, and New Opportunities. The William and Flora Hewlett Foundation, 80. Recuperado de http://www.hewlett.org/uploads/files/ReviewoftheOERMovement.pdf

Ballesteros, M., Brito, T., Comellas, M., Lojo, M., Monroy, A., Redo, M. \& Sugranyes, E. (2002). Las competencias del profesorado para la acción tutorial. España: PRAXIS.

Bolívar, A. (2007). Educación para la ciudadanía. España: Graó.

Carton, M. (1985). La educación y el mundo del trabajo. Francia: UNESCO.

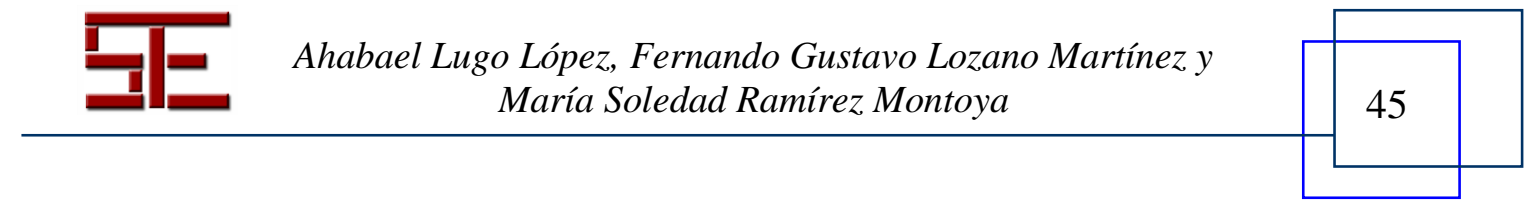




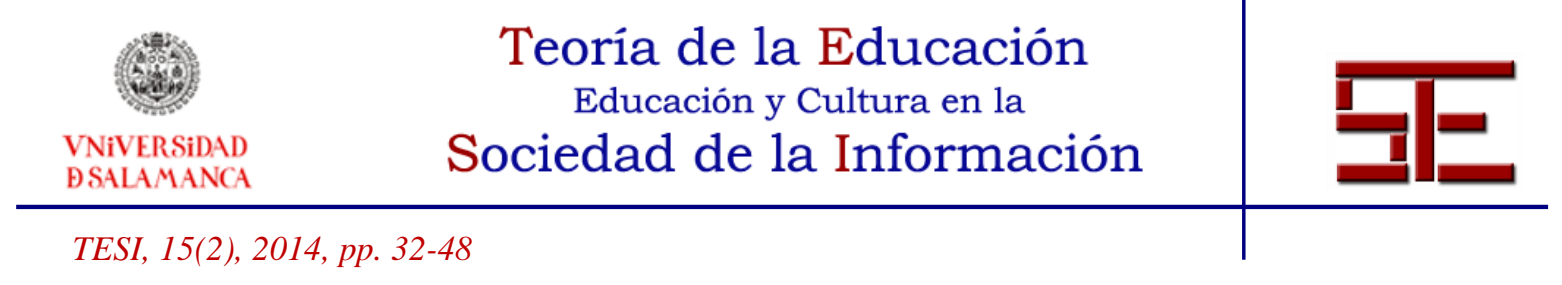

Carter, S. \& Little, M. (2007). Justifying Knowledge, Justifying Method, Taking Action: Epistemologies, Methodologies, and Methods in Qualitative Research. Qualitative Health Research, 17, 1316-1328. DOI 10.1177/1049732307306927.

D'Antoni, S. (2008). Open Educational Resources: the Way Forward. Deliberations of an international Community of interest. UNESCO-IIEP, 28. Recuperado el 20 enero, $2010 \quad$ de http://oerwiki.iiepunesco.org/images/4/46/OER_Way_Forward.pdf.

Evers, F., Rush, J. \& Berdrow, I. (1998). The bases of competence: skills for lifelong learning and employability. USA: Jossey-Bass.

Fernández, M. (2004). Competencias profesionales del docente en la sociedad del siglo $X X I$. Recuperado del sitio Web Knowledge Hub del ITESM en http://khub.itesm.mx/es/go/23309.

Fondo Mixto de Fomento a la Investigación Científica y Tecnológica CONACYT Gobierno del Estado de Tabasco (2009-2011). Proyecto financiado con registro TAB - 2008 - $\mathrm{C} 13$ - 94053 y disponible en la página Web: http://tecvirtual.itesm.mx/convenio/tabasco/homedoc.htm.

García, B., Loredo J., Luna E. \& Rueda M. (2008). Modelo de Evaluación de Competencias Docentes para la Educación Media y Superior. Revista Iberoamericana de Evaluación Educativa, 1 (3e) 124-136. Recuperado de http://www.rinace.net/riee/numeros/vol1-num3_e/art8.pdf.

Geser, G. (2007). Prácticas y recursos de educación abierta: la hoja de ruta OLCOS 2012. RUSC: Revista de Universidad y Sociedad del Conocimiento, 1 (4), 4-13. Recuperado de: http://www.uoc.edu/rusc/4/1/dt/esp/monográfico.pdf.

Gil, F., Candelas, G. \& García, C. (2012). Open Educational Resources: The Role of OCW, Blogs, and Videos in Computer Networks Classroom. International Journal of Emerging Technologies in Learning, 7 (3). Recuperado de http://online-journals.org/i-jet/login?source $=\% 2 \mathrm{Fi}$

jet\%2Farticle\%2Fview\%2F2116\%2F 2318

Guba, E. (1990). The Paradigm Dialog. USA: Saga Publications.

Hougton, J. (2007). Writing the Competency Descriptions. Library Technology Reports, 43 (2), 29-34. Recuperado de Proquest Educational Journal ID 1273423741.

Lugo, A. (2010). Competencia para usar recursos educativos abiertos para la práctica educativa [objeto de aprendizaje]. Disponible en el sitio Web:http://www.ruv.itesm.mx/convenio/tabasco/oas/ureape/homedoc.htm_Dispon ible en el repositorio abierto de la Cátedra de Investigación de Innovación en Tecnología y Educación del Tecnológico de Monterrey en http://catedra.ruv.itesm.mx//handle/987654321/250.

Murphrey, T., Sandlin, M. \& Dooley, K. (2013). Using Reusable Learning Objects (RLOs) to Share International Experiences: Faculty Perceptions and Best Practices in a College of Agriculture1. NACTA Journal, 57 (1), 47-54.

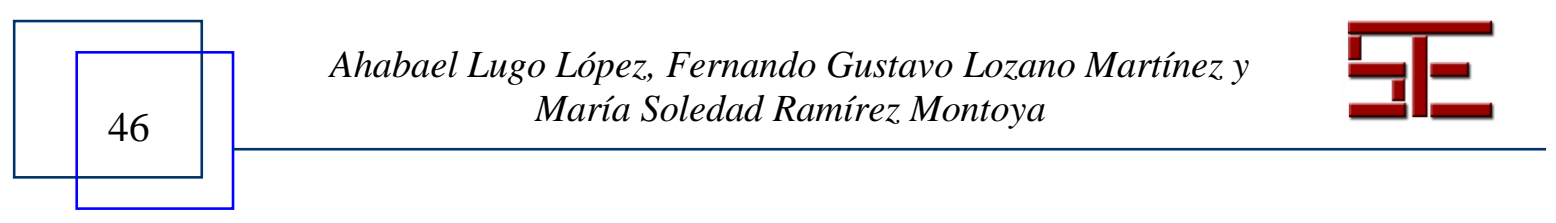




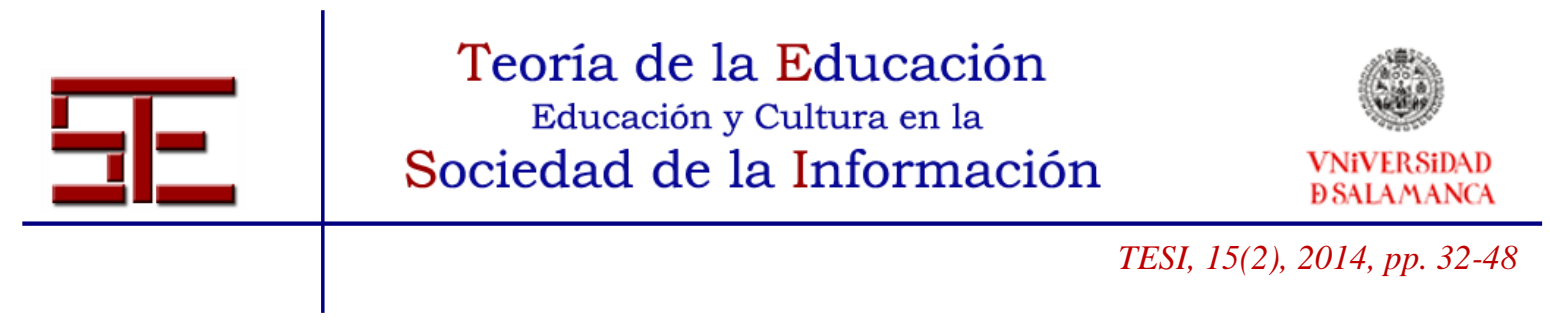

Oliveros, M. (2006). Identificación de competencias: una estrategia para la formación en el Espacio Europeo de Educación Superior. Revista Complutense de Educación, 1 (17), 101-118. Recuperado de Proquest Educational Journals ID 1937742211.

Phillips, A. (2009). What Do They Have that I Don't Have? Characteristics of National Board Certified Teachers. (ERIC Document Reproduction Service No. ED 1649160061).

Ramírez, M. S. y Valenzuela, J. R. (2010). Objetos de aprendizaje abiertos orientados a desarrollar competencias docentes para la Sociedad del Conocimiento. Ponencia presentada en Edutec 2010 "E-learning 2.0: Enseñar y Aprender en la Sociedad del Conocimiento". Bilbao, España.

Salinas, J. (1999). Enseñanza flexible, aprendizaje abierto, las redes como herramientas para la formación. EDUTEC, Revista Electrónica de Tecnología Educativa, (10). Recuperado de http://www.uib.es/depart/gte/revelec10.html.

Schettler, J. (2002). Equal Access to all. Training, 39 (1), 44-48. Recuperado de ProQuest Educational Journals ID 98913517.

Schmidt, J. (2007). Recursos Educativos Abiertos: estrategia para apertura y desarrollo social de la Educación Superior. Global University Network of Innovation. Recuperado en http://www.guni-rmies.net/news/detail.php?id=1106.

Sicilia, M. A. (2007). Más allá de los contenidos: compartiendo el diseño de los Recursos Educativos Abiertos. Revista de Universidad y Sociedad del conocimiento, 4 (1), 26-35. Recuperado el 20 de enero de 2010 de www.uoc.edu/rusc/4/1/dt/esp/sicilia.pdf

Smith, S. (2005). Learning Objects, Learning Object Repositories, and Learning Theory: Preliminary Best Practices for Online Courses. Interdisciplinary Journal of Knowledge and Learning Objects, 1, 217-228.

Sullivan, H. \& Higgins, N. (1983). Teaching for Competence. USA: Teacher College Press.

UNESCO (2004). Las tecnologías de la información y la comunicación en la formación docente. Guía de planificación. Montevideo. Recuperado de http://unesdoc.unesco.org/images/0012/001295/129533s.pdf.

Valenzuela, J. R. (2009). Competencias particulares para la práctica educativa [video]. Disponible en la Escuela de Graduados en Educación de la Universidad Virtual del Tecnológico de Monterrey, en el sitio Web: rtsp://smil.itesm.mx/ondemand/7/507/7652/3e 53ce7c/sourcevideo.itesm.mx/ege/ed5061/cap2_12_09.rm.

Vercelli, H. (2004). La conquista silenciosa del ciberespacio: Creative commons y el diseño de entornos digitales como nuevo arte regulativo en Internet. Buenos Aires. Recuperado de http://www.arielvercelli.org/lcsdc.pdf.

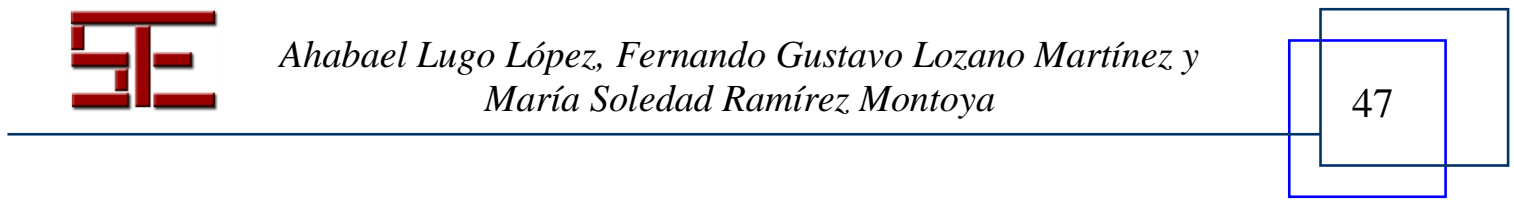




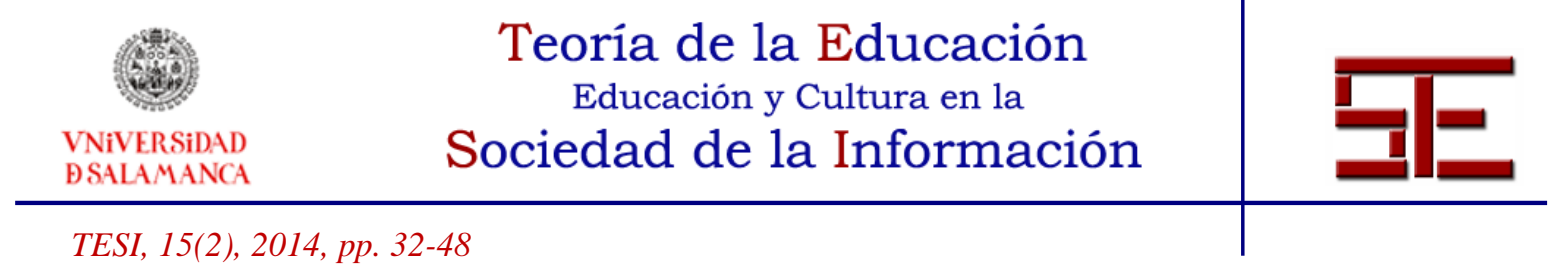

Zabalza, M. (2003). Competencias docentes del profesorado universitario. España: Narcea.

Para citar el presente artículo puede utilizar la siguiente referencia:

Lugo López, A., Lozano Martínez, F. G. y Ramírez Montoya, M. S. (2014). Objeto de aprendizaje para la formación docente orientado a desarrollar competencias para usar REA. Revista Teoría de la Educación: Educación y Cultura en la Sociedad de la Información. 15(2), 32-48 [Fecha de consulta: $\mathrm{dd} / \mathrm{mm} / \mathrm{aaaa}$ ].

http://campus.usal.es/ revistas_trabajo/index.php/revistatesi/article/view/11885

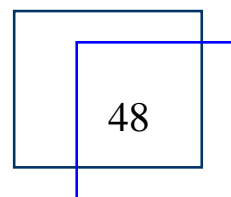

Ahabael Lugo López, Fernando Gustavo Lozano Martínez y María Soledad Ramírez Montoya 